\title{
Causal Factors and Delayed Referral of Patients of Acute Secondary Peritonitis at Herat Regional Hospital-2018-2019; a Retrospective Study
}

Sayed Azim Faqiri

Ghalib University

Mohammad Rafi Fazli ( $\nabla$ dr_rafi_fazli@yahoo.com )

Ghalib University https://orcid.org/0000-0002-1853-2182

Behyar Kiani

Ghalib University

Original Research

Keywords: acute secondary peritonitis, casual factor, laparotomy, perforation, Afghanistan

Posted Date: April 1st, 2021

DOl: https://doi.org/10.21203/rs.3.rs-368919/v1

License: (1) (i) This work is licensed under a Creative Commons Attribution 4.0 International License.

Read Full License 


\section{Abstract}

Background: acute secondary peritonitis is an inflammation of the peritoneum. Surgeons in this field face this deadly pathology, and in Afghanistan, where health services have not yet been systematically standardized, the establishment of this pathology is more likely to be challenging. The aim of this study was to address the most causal factors as well as causes of delayed referral of acute secondary peritonitis at the only tertiary referral hospital in west region of Afghanistan, Herat Regional Hospital.

Results: 496 patients were operated with diagnosis of acute secondary peritonitis. $58 \%$ of patients were male and the highest age group were being from $10-19$ years old (32.25\%). $75.21 \%$ of these patients had a delay of more than 24 hours from the onset of the first complaint to laparotomy with the highest number (23.18\%) delays for 3 days, even 2 patients had symptoms for 31 to 60 days $(0.40 \%)$. The most common symptoms were abdominal pain with $97 \%$, followed by nausea and vomiting $81 \%$ and anorexia $74 \%$. Among all pathologies, acute appendicitis was the most common cause of peritonitis $(64.5 \%)$ followed by small bowel perforation (9.7\%) and peptic ulcer perforation (8.5\%). According to late referral $79 \%$ started medical treatment after consulting a general doctor, $15 \%$ didn't come to health facilities due to long distances and $6 \%$ started home treatment due to wrong believes.

Conclusion: According to our research, there is still some acute abdomen patients who come late to health facilities and this is because of the limited resources, cultural issues and lack of the knowledge of the general doctors. In order to decrease the number of these patients we need to expand knowledge of both patients and health staffs, in another word consulting abdominal pain patients should be obligatory by surgeons.

\section{Introduction:}

Acute secondary peritonitis is one of the most dangerous pathologies that challenges surgeons. The treatment of peritonitis was done in 1926 by the German surgeon M. Kirshner [1], And since then, in the treatment of this deadly disease, an urgent and fundamental place has been allocated for urgent and timely surgery $[2,3]$.

Although doctors have made significant progress in the management of patients with acute peritonitis in recent decades, the mortality rate of these patients are still reported to be between 19 and $70 \%[1,4,5]$. The cause of $90 \%$ of deaths in these patients were the delay in the transfer and emergency surgery in the hospital $[5,6]$. Researches show that the main causes of acute secondary peritonitis are perforation of hollow organs caused by acute inflammatory diseases, trauma, intestinal obstruction, malignant and begnin tumors $[7,8,9]$.

Complications like surgical infection, abdominal abscess, fecal fistulas, and thoracic complications are the causes of mortality and morbidity among them [10].

\section{Method:}


This retrospective study was performed by studying the recorded archive of peritonitis surgery patients' files in Herat Regional Hospital. The study period was from 2018 to 2019 and all the medical records were studied and written in a questionnaire. 496 laparotomies were done due to acute secondary peritonitis. According to the questionnaire, the required information was obtained from the file of these patients, first a group of 5 doctors were trained who to take the necessary information and then they were sent to collect the data. Included criteria was the patients who was operated by laparotomy due to acute secondary peritonitis and excluded criteria was the patients whom had local peritonitis, acute abdomen without peritonitis, peritonitis due to trauma and acute peritonitis who died without laparotomy. Demographic parameters, etiology, signs and symptoms, delay in admission, lab investigations, condition on discharge were the mainly criteria. The data were analyzed by SPSS 24 .

\section{Results:}

From 2018 to 2019, a total number of 17,745 patients were admitted to the Herat Regional Hospital. Of these, 8585 were men and 9160 were women. It is noteworthy that the surgery department of Herat Regional Hospital has covered emergency pediatric and adolescent surgery, trauma surgery, routine surgery, urological surgery and gynecological surgery from Herat and neighboring provinces.

Of the 17,745 patients who underwent surgery, 496 were diagnosed with acute secondary peritonitis after laparotomy, representing 2.8\% of the total surgical patients between 2018 and 2019 (based on operational findings). Figure 1: The percentage of peritonitis patients in Herat Regional Hospital, 2018 201.

Among 496 patients with acute secondary peritonitis, 290 were men (58\%) and 206 (42\%) were women. Among these patients, different age groups were observed, with the highest age group being from 10-19 years old (32.25\%), followed by $20-29$ years old (23.99\%) and lowest age group $70-80$ years old (2.62\%). Figure 2: Distribution of General peritonitis by age.

Another important feature that plays a significant role in the formation of peritonitis is the length of time that the patient has spent from the first symptoms out of hospital to the time of laparotomy in the operating room. Of the 496 patients with general peritonitis, $75.21 \%$ had a delay of more than 24 hours from the onset of the first complaint to laparotomy. The highest number of patients with $23.18 \%$ had delays for 3 days and even some patients has symptoms for 4 to 8 weeks $(1.81 \%)$. 
Table 1

The delayed time

\begin{tabular}{|lll|}
\hline The onset of symptoms & Number of patients & Percent \\
\hline Less than 6 hours & 22 & $4.43 \%$ \\
\hline 6 to 12 hours & 23 & $4.63 \%$ \\
\hline 1 day & 78 & $15.73 \%$ \\
\hline 2 days & 89 & $17.94 \%$ \\
\hline 3 days & 115 & $23.18 \%$ \\
\hline 4 days & 59 & $11.89 \%$ \\
\hline 5 days & 39 & $7.86 \%$ \\
\hline 6 days & 14 & $2.82 \%$ \\
\hline 7 days & 23 & $4.63 \%$ \\
\hline 8 to 10 days & 15 & $3.02 \%$ \\
\hline 11 to 20 days & 10 & $2.06 \%$ \\
\hline 21 to 30 days & 7 & $1.41 \%$ \\
\hline 31 to 60 days & 2 & $0.40 \%$ \\
\hline Total & 496 & $100.00 \%$ \\
\hline
\end{tabular}

The reason for the late arrival of patients to the hospital was the following:

- (79\%) - went to see a general doctor and started medical treatment

- $(15 \%)$ came late due to distance from the city and health centers

- (6\%) started treatment at home (with the advice of non-professionals)

Analysis of the data shows that between $74-100 \%$ of patients initially complained of abdominal pain, nausea and vomiting and anorexia, with abdominal pain occurring in approximately $97 \%$ of patients. 
Table 2

complains

\begin{tabular}{|ll|}
\hline Signs and symptoms of peritonitis patients & Percent \\
\hline Abdominal pain & $97 \%$ \\
\hline Nausea and vomiting & $81 \%$ \\
\hline Anorexia & $74 \%$ \\
\hline Constipation & $29 \%$ \\
\hline Obstipation & $22.50 \%$ \\
\hline Abdominal distension & $21.50 \%$ \\
\hline Weakness and fatigue & $19 \%$ \\
\hline Fever & $10.50 \%$ \\
\hline Diarrhea & $2.50 \%$ \\
\hline Thirst & $2 \%$ \\
\hline Dyspnea & $1.50 \%$ \\
\hline
\end{tabular}

The following table shows the conditions and pathologies that have caused peritonitis in the above patients: Among all pathologies, acute appendicitis is the most common cause of peritonitis $(64.51 \%)$. 
Table 3

causes

\begin{tabular}{|lll|}
\hline Casual factors of peritonitis & Number & Percent \\
\hline Acute Appendicitis & 320 & $64.51 \%$ \\
\hline Small bowl perforation & 48 & $9.70 \%$ \\
\hline Peptic Ulcer Perforation & 42 & $8.50 \%$ \\
\hline Unknown & 24 & $4.85 \%$ \\
\hline Hydatid cyst & 9 & $1.81 \%$ \\
\hline Ectopic pregnancy & 8 & $1.61 \%$ \\
\hline Mesenteric ischemia & 5 & $1 \%$ \\
\hline Colonic Perforation & 16 & $3.22 \%$ \\
\hline Uterus perforation & 5 & $1 \%$ \\
\hline Rupture of Ovarian cyst & 4 & $0.80 \%$ \\
\hline Rupture of spleen & 4 & $0.80 \%$ \\
\hline Cholecystitis & 4 & $0.80 \%$ \\
\hline Pancreatitis & 3 & $0.60 \%$ \\
\hline Urinary bladder perforation & 2 & $0.40 \%$ \\
\hline Foreign body & 1 & $0.20 \%$ \\
\hline liver tumor & 1 & $0.20 \%$ \\
\hline Total & 496 & $100.00 \%$ \\
\hline
\end{tabular}

The hospital stay time in which patients spent in the surgery ward is shown in table below: 
Table 4

Bed occupancy

\begin{tabular}{|lll|}
\hline Number of days & Number of patients & Percentage \\
\hline$<4$ & 49 & $9.88 \%$ \\
\hline 4 & 98 & $19.76 \%$ \\
\hline 5 & 69 & $13.92 \%$ \\
\hline 7 & 69 & $13.92 \%$ \\
\hline 8 & 53 & $10.68 \%$ \\
\hline 9 & 42 & $8.46 \%$ \\
\hline 10 & 36 & $7.26 \%$ \\
\hline$>10$ & 39 & $7.86 \%$ \\
\hline Total & 41 & $8.26 \%$ \\
\hline
\end{tabular}

As seen in table above $19.76 \%$ in the hospital for 4 days after surgery, $13.92 \%$ was for 5 to 6 days in the hospital and even $8.26 \%$ had more than 10 days in the hospital.

$90.12 \%$ of the patients were recovered from the surgery, 34 patients had transferred to other centers (6.85\%) for better treatment and 15 patients (3.03\%) has died due to complications.

\section{Discussion:}

This study outlines the percentage of acute secondary peritonitis patients, distribution of acute secondary peritonitis by age, sex, etiology, symptoms, outcomes of surgically managed, casual factors and reason of delayed referral of patients at Herat Regional Hospital at 2018-2019.

In our study, the maximum incidence of peritonitis was found to be between the age of 10-19 years accounting for $32.25 \%$, followed by $20-29$ years (23.99\%), in 30-39 years $(12.11 \%)$ and the least age was between $70-80$ about $2.62 \%$. In a study by Raj Kumar et al in India $23.53 \%$ patients were in age group $21-30$ years, $13.73 \%$ patients in age-group of $31-40$ years and $1.96 \%$ patients in age group of $71-$ 80 years [11]. In another study by Varun Raju Thirumalagiri, 30\% patients were between 20-29 years, 6\% patients between $30-39,14 \%$ patients between $40-50$ years old [7]. In another study conducted by Raj Kumar et al in a tertiary care hospital $54.25 \%$ patients were in age group of 21-50 years old [12]. Our research is equal to Raj Kumar and Thirumalagiri researches in the $2 n d$, 3th and 7 th decades of live. Our research showed that $56.24 \%$ of patients are in the 2 nd and third decades of life which is the age of working, education and reproduction. 
In our study among 496 patients $58 \%$ were male and $42 \%$ were female. In study of Raj Kumar et al $86.26 \%$ of the patients were male and $13.73 \%$ were female and male to female ratio was $6.26: 1$ [11]. In another study by M.R. Shanker et al $76 \%$ of patients were male and $24 \%$ females and a male to female ratio was 2.84:1 [13]. In another study by Shahida Parveen Afridi et al $68.3 \%$ of patients were male and $31.7 \%$ were female with the ration of 2.1:1 [14]. Our findings in the term of sex are different from researches by Afridi, Raj and Shanker. This difference is because Herat Regional Hospital is the only tertiary and referral hospital in West Region of Afghanistan which accepts all critical patients. On the other hand, as mentioned before Herat Regional Hospital is accepting all kinds of patients even gynecological patients.

$2.8 \%$ of emergency operations in our hospital in the department of general surgery were for peritonitis. This finding is not comparable with many other studies. M. R. Shanker et al, in India in 2018 reported an incidence rate of $26 \%$ [13]. Arveen et al in a study from 2006-2008 at JIPMER reported an incidence rate of $25 \%$ [15]. This big difference might be because Herat Regional Hospital accepts all kinds of patients including routine and trauma, on the other hand we excluded trauma peritonitis from our research so this may have significant impact on the incidence.

In our study we observed that the most common etiology of acute secondary peritonitis was acute appendicitis (64.51\%), small bowel perforation (9.7\%), peptic ulcer perforation (8.50\%), colonic perforation (3.22\%). The researches by others are summarized at the following chart:

Table 5

casual factors

\begin{tabular}{|lllllll|}
\hline $\begin{array}{l}\text { Casual } \\
\text { factors }\end{array}$ & $\begin{array}{l}\text { Our } \\
\text { research }\end{array}$ & $\begin{array}{l}\text { Raj } \\
\text { kumar et } \\
\text { al 12 }\end{array}$ & $\begin{array}{l}\text { Jonathan } \\
\text { Sameul et al } \\
16\end{array}$ & $\begin{array}{l}\text { Atul Kumar } \\
\text { Vyas et al 17 }\end{array}$ & $\begin{array}{l}\text { Shanker } \\
\text { et al 18 }\end{array}$ & $\begin{array}{l}\text { Ohene- } \\
\text { Yeboah M } \\
21\end{array}$ \\
\hline $\begin{array}{l}\text { Acute } \\
\text { appendicitis }\end{array}$ & $64.51 \%$ & $9.80 \%$ & $22 \%$ & $18 \%$ & $44 \%$ & $43.1 \%$ \\
\hline $\begin{array}{l}\text { Peptic ulcer } \\
\text { perforation }\end{array}$ & $8.50 \%$ & $77.13 \%$ & $11 \%$ & $57 \%$ & $36 \%$ & $12 \%$ \\
\hline $\begin{array}{l}\text { Small bowel } \\
\text { perforation }\end{array}$ & $9.7 \%$ & $7.84 \%$ & $11 \%$ & $13 \%$ & -- & $10.50 \%$ \\
\hline $\begin{array}{l}\text { Colonic } \\
\text { perforation }\end{array}$ & $3.22 \%$ & - & - & - & - & - \\
\hline
\end{tabular}

According to our findings the most cause of peritonitis is acute appendicitis (64.51\%). Our results are consistent with western experience [20], Shanker (44\%) and Ohene-Yeboa (43.1\%) however some series from India have shown different results Vyas (18\%) and Kumar (9.8\%). This difference clarifies that the number of peritonitis due to acute appendicitis is still high in Afghanistan. In a study by varun Raju Thirumalagiri et al [7] and Rajender Singh Jhobta [19] colonic perforation stands 4\%, while in our research 
is $3.22 \%$, which is approximately the same as others. As you see the table above in the field of small bowel perforation, our research is the same as others. Peptic ulcer perforation in our research is the same with the researches by Jonathan Sameul et al and Ohene-Yeboah et al but there is still big difference with Raj Kumar and Atul Kumar researches which might be that in Raj Kumar and Atul Kumar the number of studied patients are less, on the other hand perforation of peptic ulcer is one of the most cases of general peritonitis in India [27].

The mortality rate in our study was $3.03 \%$ while it was $8 \%$ in the study by Thirumalagiri VR [7], $10 \%$ in study by Jhobta [19] and $8.82 \%$ in study of SK. Doklestic[22]. In fact, our research is almost the same as above researches in the incidence of mortality because we referred our critical patients $(6.85 \%)$ to other centers and we don't know about their results.

Our research regarding the frequency of symptoms are with the following: $97 \%$ abdominal pain, $81 \%$ nausea and vomiting, $51 \%$ constipation and obstipation, $21.50 \%$ abdominal distention and $10.50 \%$ fever. Other researches regarding the symptoms are as follow:

Table 6

symptoms

\begin{tabular}{|llllll|}
\hline $\begin{array}{l}\text { Frequency of } \\
\text { symptoms }\end{array}$ & $\begin{array}{l}\text { Our } \\
\text { research }\end{array}$ & $\begin{array}{l}\text { M.R. Shanker et } \\
\text { al } \mathbf{1 8}^{\text {R }}\end{array}$ & $\begin{array}{l}\text { Raj Kumar et } \\
\text { al 12 }\end{array}$ & $\begin{array}{l}\text { Atul Kumar } \\
\text { Vyas }{ }^{\mathbf{1 7}}\end{array}$ & $\begin{array}{l}\text { Sivaram et } \\
\text { al 23 }\end{array}$ \\
\hline Abdominal pain & $97 \%$ & $100 \%$ & $100 \%$ & $100 \%$ & $100 \%$ \\
\hline Nausea/vomiting & $81 \%$ & - & - & $64 \%$ & $55 \%$ \\
\hline Constipation & $51 \%$ & $48 \%$ & - & $84 \%$ & - \\
\hline $\begin{array}{l}\text { Abdominal } \\
\text { distention }\end{array}$ & $21.5 \%$ & $52 \%$ & $86.27 \%$ & $88 \%$ & $44 \%$ \\
\hline fever & $10.5 \%$ & - & $33.99 \%$ & $34 \%$ & $25 \%$ \\
\hline
\end{tabular}

As seen in above table, abdominal pain, constipation and vomiting are almost the same in our research with other researches. In our research abdominal distention and fever has big difference with researches by Raj Kumar and Atul Kumar. The difference might be due to a long gap between the beginning of symptoms and coming to hospital and we also have some uncommon peritonitis like peritonitis due to uterus, ovarian cyst, spleen, liver tumor and many more

In our research, there was a significant gap from onset of symptoms to the surgery time. From 496 patients $75.21 \%$ had a delay of more than 24 hours from the onset of the first complaint to laparotomy. The highest number of patients with $23.18 \%$ had delays for 3 days and even some patients has symptoms for 4 to 8 weeks (1.81\%). A research by Atul Kumar Vyas et al [17] showed that $64 \%$ of patients presented at variable times beyond 24 hours from onset of symptoms. Kotiso et al. noted $25 \%$ mortality rate in patients with symptoms over 2 days in compare to $7.6 \%$ less than 2 days [24]. In a 
research by Ranju Singh et al among 84 patients $100 \%$ who died had symptoms more than 3 days [26]. Timing of presentation over 24 hours was found to be a significant factor in developing of post-operative mortality and morbidity [25].

\section{Conclusion:}

Acute secondary peritonitis is still high in west region of Afghanistan specially among illiterate, low socioeconomic class, low culture class and rural settings. The most common causes of secondary peritonitis in our society is acute appendicitis while in other countries appendicitis-peritonitis is not common. Most of our patients came late to Herat Regional Hospital so we have noticed that delayed referral of patients are due to many reasons like un-education, lack of health facilities, wrong beliefs, lack of skilled health workers, traditional treatments, damaged health systems, lack of transportation and road facility. Treatment outcome would be better by early diagnosis, better health facilities and better skilled health care workers. We have noticed that many patients with acute abdominal pain still do not benefit from timely consultation with a specialist surgeon. At the first line of examination, acute abdominal patients are still mediated by GP doctors or medical personnel. The conditions of the country and the culture of the society also had an effect on the patients with acute abdominal pain. We have found that signs and symptoms are still significant and helpful for diagnosis of acute secondary peritonitis specially in limited resources areas like Afghanistan where diagnostic tools are less and costly. Most of our patients are in the second and third decades of life, the time of working, education, reproduction and many more. In order to have a better outcome, all patients with abdominal pains must be consulted with surgeons and all the people and health personnel should be aware of consequences of delay in diagnosis of abdominal pain patients.

\section{Declarations:}

Acknowledgements: Thanks to Herat Regional Hospital for helping to make this research.

Funding: None

Conflict of interest: All authors have no conflict of interest.

Ethical standards: ethical approval and written consent were taken by Ghalib University Research Committee

Consent for publication was approved by Ghalib Univeristy Research committee

Availability of data and materials: not applicable

\section{References:}

1. Kirschner M, The treatment of acute purulent free peritonitis. Arch Klin Chir.1926 142:253-311 
2. Murphy JB: IV treatment of perforative peritonitis: general free suppurative. Ann Surg1908.47(6):870.

3. L N Dorairajan, S Gupta, S V Deo, et al, Peritonitis in India-a decade's experience," Tropical Gastroenterology, 1995 vol. 16, no. 1

4. Prajakt V Patil, Manmohan M Kamat, Milan M Hindalekar Spectrum of Perforative Peritonitis- A Prospective Study of 150 Cases. Bombay Hospital Journal 2012;54(1):38-50

5. Jawad NM, Ahmed Abd Al Raheem Al Zubaydi Factors Affecting Morbidity and Mortality Rates in the Management of Perforated Duodenal Ulcer. Iraqi J Comm Med. 2006;19:(1)69-74

6. Kamble, Ranjeet S., Mansha Singh, et al "Prognostic factors in perforative peritonitis: an observational study. International Surgery Journal2016;3.3:1082-1092.

7. Thirumalagiri VR, Chandra H Acute peritonitis secondary to hollow viscous perforation: a clinical study. Int Surg J. 2017; 4(7):2262-9

8. Yadav D, Garg P Spectrum of perforation peritonitis in Delhi: 77 cases experience. Indian J Surg. 2012; 75(2):133-7

9. Bali R, Verma S, Agarwal P et al, Perforation peritonitis and the developing world. ISRN Surg. 2014:14.

10. Bose SM, Kumar A, Chaudhary A, et al Factors affecting mortality in small intestinal perforation. Indian J Gastroenterology. 1986, 5(4):261-3.

11. Kumar R, Gupta R, Sharma A, et al Clinical Presentation and Findings in Secondary Generalised Peritonitis among the Patients Admitted in a Tertiary Care Hospital in Northern Part of India; 2018

12. Kumar R, Gupta R, Sharma A, et al Descriptive Study Regarding the Etiological Factors Responsible for Secondary Bacterial Peritonitis in Patients Admitted in a Tertiary Care Hospital in Trans Himalayan Region. 2016

13. Kamble, Ranjeet S., Mansha Singh, et al "Prognostic factors in perforative peritonitis: an observational study." International Surgery Journa/2016, 3.3 1082-1092

14. Afridi SP, Malik F, Ur-Rahman S, et al Spectrum of perforation peritonitis in Pakistan: 300 cases Eastern experience. World Journal of Emergency Surgery. Dec2008;3(1):1-5

15. Arveen S, Jagdish S, Kadambari D Perforated peptic ulcer in South India: an institutional perspective. World J Surg. 2009; 33(8):1600-4

16. Samuel JC, Qureshi JS, Mulima G, et al An Observational Study of the Etiology, clinical presentation and outcomes associated with peritonitis in Lilongwe, Malawi. World journal of Emergency surgery 2011;6(1):1-5

17. Vyas AK, Tanwani R, Raghuvanshi RS, et al A prospective study of perforation peritonitis in a tertiary health care centre of central India. Ann Int Med Dental Res 2017;3(2).

18. Shanker MR, M Nahid, Prajwal S A clinical study of generalised peritonitis and its management in a rural setup. Int Surg J 2018. Nov;5

19. Jhobta RS, Attri AK, Kaushik R, et al Spectrum of perforation peritonitis in India-review of 504 consecutive cases. World journal of Emergency surgery2006. 1(1):1-4 
20. Malangoni, Mark A., and Tazo Inui "Peritonitis-the Western experience." World journal of emergency Surgery2006 1.1 1-5

21. Ohene-Yeboah M Causes of acute peritonitis in 1188 consecutive adult patients in Ghana. Tropical Doctor. 2005 35: 84-85. 10.1258/0049475054036788

22. Doklestić, S K., et al "Secondary peritonitis-evaluation of 204 cases and literature review." Journal of medicine and life2014 7.2 132.

23. Sivaram P, Sreekumar A Preoperative factors influencing mortality and morbidity in peptic ulcer perforation. Eu J Trauma Emerg Surg. 2017 44(2):251-7

24. Kotiso B, Abdurahman Z Pattern of acute abdomen in adult patients in Tikur Anbessa Teaching Hospital, Addis Ababa, Ethiopia. East and Central African Journal of Surgery2007. 12: 47-52

25. Malik S, Singh A, Sidhu DSet al A prospective study to assess clinical profile and golden period for operative intervention in patients with perforation peritonitis. Int Surg J 2018;5: 1492-8.

26. Singh, Ranju, et al "Preoperative predictors of mortality in adult patients with perforation peritonitis." Indian journal of critical care medicine: peer-reviewed, official publication of Indian Society of Critical Care Medicine2011 15.3157

27. Arveen, Sankar, Sadasivan Jagdish, et al "Perforated peptic ulcer in South India: an institutional perspective." World journal of surgery2009; 33.81600-1604.

\section{Figures}

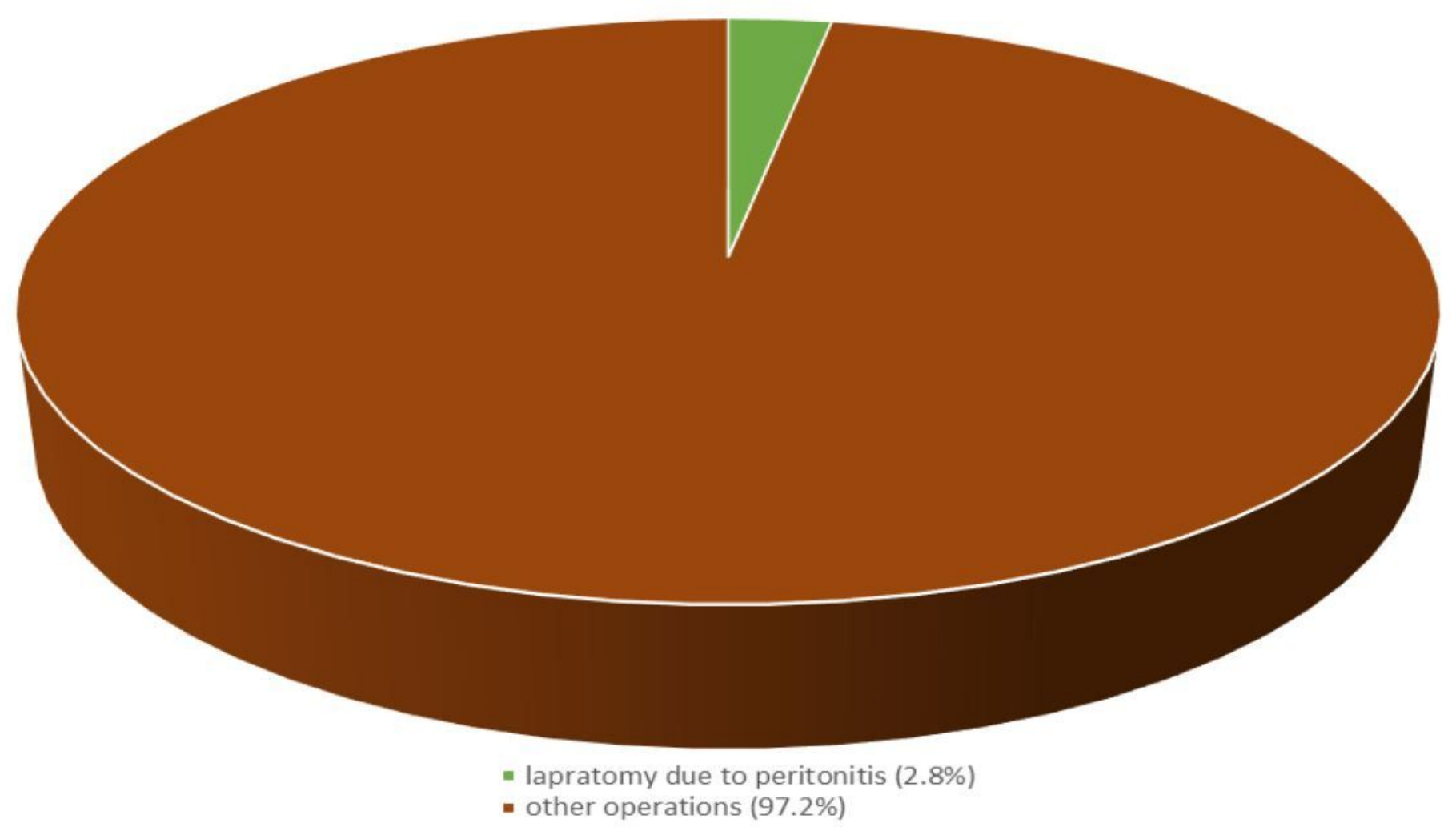


Figure 1

The percentage of peritonitis patients in Herat Regional Hospital, 2018-201.

$35.00 \%$

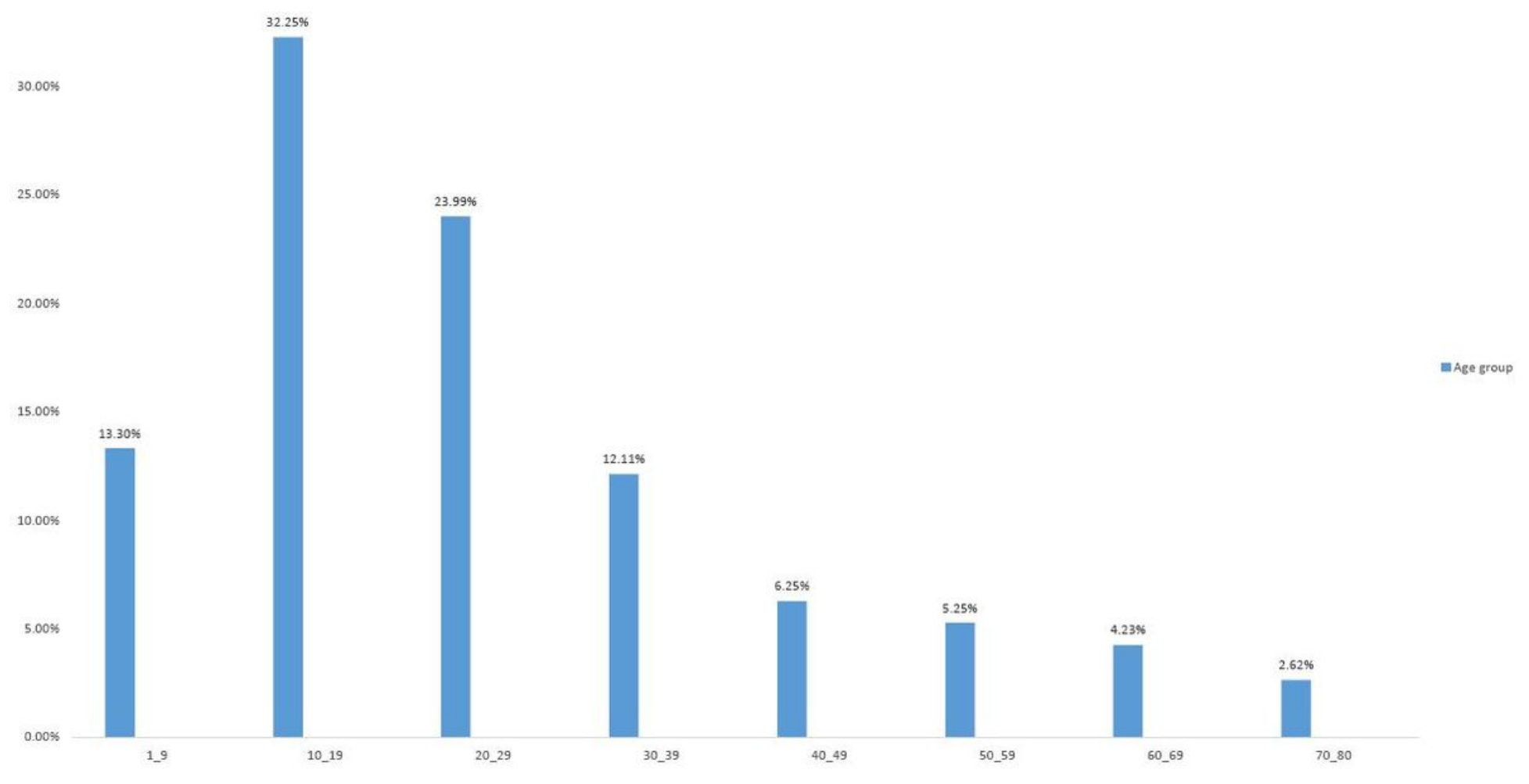

Figure 2

Distribution of General peritonitis by age. 